\title{
Peertechz
}

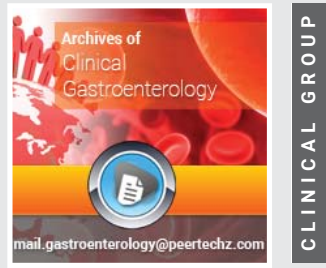

\section{Quality of life and symptoms of anxiety and depression in patients affected by ulcerative colitis}

\author{
Fernandes ACS ${ }^{1}$, Tomazoni El1 and Benvegnú DM²* \\ ${ }^{1}$ Undergraduate Student in Nutrition at Federal University of Fronteira Sul (UFFS) Campus Realeza, PR, \\ Brazil \\ ${ }^{2} \mathrm{PhD}$ Profesor at Federal University of Fronteira Sul (UFFS), Campus Realeza, PR, Brazil
}

Received: 17 August, 2020

Accepted: 28 August, 2020

Published: 29 August, 2020

*Corresponding author: Benvegnú DM, PhD, Federal University of Fronteira Sul, Campus Realeza, PR, Brazil, Tel: +55(46) 99974-7739;

Email: dalilabenvegnu@yahoo.com.br

Keywords: Mental disease; Psychiatric disease; Inflammatory bowel disease; Psychological symptoms

https://www.peertechz.com

\section{Check for updates}

\section{Abstract \\ Introduction: Ulcerative Colitis (UC) is an Inflammatory Bowel Disease (IBD) that can be divided into two periods: active and remission. Individuals affected by this pathology can manifest symptoms of anxiety and depression, as well as low quality of life, due to the symptomatology of this disease when active. \\ Objective: Demonstrate the relationship between anxiety and depression with UC and its influence on quality of life. \\ Material and methods: The present study involved 97 individuals affected with UC, who were assessed through the application of the HADS and IBDQ on the social network Facebook, as well as their individual feeds. The survey began after approval by the Research Ethics Committee of the Federal University of Fronteira Sul, upon} obtaining informed consent from the patients.

Results: The majority of the assisted participants was female, white, married, and residents of southwest Brazil. A prevalence of symptoms of anxiety and depression was observed in individuals with low quality of life and status of disease activity.

Discussion: The results show that individuals who exhibited an active disease status presented a lower quality of life, anxiety, and depression.

\section{Introduction}

Ulcerative Colitis (UC) is an idiopathic, chronic disease that involves the mucosa of the colon and rectum, resulting in diffuse friability and erosions, with possible bleeding [1]. UC is classified as an Inflammatory Bowel Disease (IBD), along with Crohn's Disease (CD) and its main symptoms include diarrhea, enterorrhagia, tenesmus, the elimination of mucus, and abdominal pain-like colic [2]. These symptoms, manifested during the disease's active stage, are generally used to classify severity, with the asymptomatic stage being known as remission.

The diseases more frequent in young adults, from around the second to fourth decade of life, followed by individuals aged 60 years or older, depending on genetic predisposition [3]. The incidence of UC varies between 7-9 cases per every 100.000 individuals. In North America and Europe, the number of cases fluctuates between 90 and 505 [4]. Regarding ethnicity, a higher frequency is observed in white individuals, regardless of sex $[5,6]$.

The high morbidity rates caused by UC significantly affect the quality of life of patients, leading them to withdraw from social conviviality and, often, their work activities [3].

The uncertain nature of the disease and its association with serious complications and the possible need for surgery or hospitalization to control symptoms render individuals with IBD more susceptible to develop anxiety or depression, especially during the stages of symptomatic intensification of the disease $[7,8]$. According to the study by Freitas, et al. 
(2015), symptoms of anxiety and depression may cause the onset of the disease, and their aggravation during the active stage can lead to depression, influencing treatment adherence [9]. Thus, depression and anxiety can considerably influence, along with other etiological factors, the emergence of UC, possibly through psychoimmunoneurological mechanisms [8].

Therefore, the objective of the present study was to investigate the presence of anxiety and depression symptoms in Brazilian individuals with UC, as well as understand the disease's relationship with quality of life.

\section{Material and methods}

The present cross-sectional study involved 97 adult individuals, who were included according to the following criteria: residing in any region of Brazil, age between 21 and 59 years, diagnosis of UC by a medical professional. From March to August 2016, the study population was selected from private groups on the social network Facebook destined to individuals diagnosed with IBD, whose purpose is to discuss disease progression, gather new information on the issue, and to get to know the different stories of other related group participants. We highlight that Facebook was the only social network selected due to the large number of participants affected with UC and the ease in contacting them. The individuals were invited randomly and individually to participate in the study, and the inclusion criteria were explained at the time of invitation.

This study was approved by the Research Ethics Committee of the Federal University of Fronteira Sul (UFFS), under Certificate of Presentation for Ethical Assessment \#51795915.9.0000.5564. Through a brief description, all participants were informed regarding the study objectives and procedures and, by online communication, were submitted to the Hospital Anxiety and Depression Scale (HADS) questionnaire to verify the presence of symptoms of anxiety and depression in these individuals.

The HADS questionnaire was translated into several languages and validated in Portuguese in 1995. The survey contains 14 items, which are divided into subscales of anxiety and depression. Each of the items can be scored from 0 to 3, with a maximum score of 21 points for each subscale. There are two cutoff points indicated for use in both subscales: anxiety or depression (absence - from 0 to 8; presence - greater than or equal to 9) [10].

Regarding the quality of life of individuals with UC, the parameter was assessed through the Inflammatory Bowel Disease Questionnaire (IBDQ). According to Meyer (2009), the instrument was developed in 1988 in the United States and was translated and validated in Brazilian Portuguese. The author also concluded that the IBDQ is a reliable tool, with good reproducibility, that reflects the main changes that occur in the health status of patients with IBD [3].

Currently, the IBDQ contains 32 items, comprising four domains: 1) intestinal symptoms, 2) systemic symptoms, 3) social aspects, and 4) emotional aspects, and the response options are presented in multiple-choice format with seven alternatives. The sum of all domains results in the total score, classifying the quality of life as: $\leq 100$ points - low; 101 to 150 points - regular; 151 to 199 points - good, and $\geq 200$ points excellent.

Information on the sociodemographic variables (age, sex and region of Brazil in which they reside) was also obtained through the reports of the participants. The self-report was used as a criterion to obtain information about the disease activity time (remission or active), as well as for anthropometric measurements (current weight and height), so the data depended on the ability of each participant to accurately inform the data indicated. These measures were used to determine the anthropometric profile of the participants through the Body Mass Index (BMI) for adults of both sexes, as proposed by the World Health Organization (WHO, 2002). Subsequently, the anthropometric profile of the participants was classified as underweight, eutrophic, overweight and obese.

Data were analyzed using Microsoft Excel ${ }^{\circledR}$ using descriptive statistics (mean, standard deviation and percentage), as well as using Statistica software, versions 8.0 and 13.2. The multiple linear regression test was used to relate the dependent variables (symptoms of depression and anxiety) versus the independent variables (intestinal symptoms, systemic symptoms, social aspects, emotional aspects and their total sum).

\section{Results}

A total of 97 individuals, with an average age of $31 \pm 7.79$ years, were included in the present study. Most participants were women $(\mathrm{n}=80)$, totaling $82.47 \%$, and $17.53 \%$ were men $(n=17)$. As for ethnicity, $65.98 \%(n=64)$ of the individuals declared themselves to be white; $24.74 \%(n=24)$ brown; and $7.22 \%(n=7)$ black, the other participants did not respond. Regarding the region of Brazil in which each participant reported residing, $47.42 \%(\mathrm{n}=46)$ were from the Southeast, $23.71 \%(n=23)$ from the South, $17.53 \%(n=17)$ from the Northeast , 9.28\% $(n=9)$ from the Midwest and $2.06 \%(n$ = 2) from the North. Regarding marital status, $48.45 \%$ ( $\mathrm{n}=$ 47 ) of the individuals were married and $38.14 \%(n=37)$ were single, the other participants did not respond. Considering the anthropometric profile, $54.64 \%(n=53)$ were classified as eutrophic, $23.71 \%(n=23)$ overweight, $17.53 \%(n=17)$ as obese and $4.12 \%(n=4)$, the minority, as underweight. After analyzing the anthropometric profile and the presence of symptoms of anxiety and depression, none of the underweight individuals manifested symptoms of both, with HADS scores between 3 and 7. Among the eutrophic, 30.93\% ( $\mathrm{n}=30)$ presented symptoms anxiety and $24.74 \%(\mathrm{n}=24)$ depression. Meanwhile, in the overweight group, $16.49 \%(n=16)$ had anxiety, while $9.28 \%(n=9)$ had depression. Among the obese, $11.34 \%(n=11)$ presented symptoms of anxiety and $8.25 \%(n=$ 8 ), of depression. There was no significant difference between the classifications of nutritional status and its relationship with anxiety and depression.

When analyzing the data obtained by the IBDQ only one individual from the eutrophic (1.85\%) and obese $(5.88 \%)$ groups obtained an excellent quality of life assessment. The

Citation: Fernandes ACS, Tomazoni El, Benvegnú DM (2020) Quality of life and symptoms of anxiety and depression in patients affected by ulcerative colitis. Arch 
prevalence was good quality of life in the eutrophic group $(44.44 \% ; n=24)$ and regular quality of life in the obese group $(47.06 \% ; n=8)$. Underweight and overweight individuals ranged between low and good quality of life, with prevalence of good quality of life in the low weight group $(50 \% ; n=2)$ and regular quality of life in the overweight group (40,90\%; $\mathrm{n}=9$ ). There was no significant difference when related to the participants' quality of life and nutritional status.

The quality of life of most participants was classified according to the IBDQ, as follows: $11 \%(n=36)$ had regular or good quality, $71 \%(\mathrm{n}=23)$, low quality and only $07 \%(\mathrm{n}=2)$ had an excellent quality of life. Regarding the relationship between the individuals' quality of life and the periods of activity and disease remission, $49.48 \%(n=48)$ of the individuals had an active disease state, of which $45.83 \%(n=22)$ were classified as regular quality of life; $37.5 \%(n=18)$ low quality of life and $16.66 \%(n=8)$ good quality of life. None of the participants had an excellent quality of life. When correlating the periods of disease activity and quality of life, $50.52 \%(n=49)$ of the individuals showed a state of remission, of which $57.14 \%(\mathrm{n}=$ 28) were classified as having good quality of life; $26.53 \%$ ( $n=$ 13) regular quality of life; $12.24 \%(n=6)$ low quality of life and $4.1 \%(n=2)$ excellent quality of life. There was no significant difference when comparing the period of remission and activity and quality of life.

Of the total number of individuals participating in the study, the majority $(65.52 \%, \mathrm{n}=57)$ presented symptoms of anxiety, with a mean and standard deviation of $10 \pm 4.72$, respectively, in this population, according to HADS. Depression symptoms were observed in $28.87 \%(n=28)$ of the individuals, with an average of $8 \pm 4.00$, based on HADS. In addition, a significant result $(\mathrm{p}<0.005)$ was found when comparing anxiety symptoms with the diagnosis of CU using the multiple linear regression test.

The correlation of anxiety symptoms with IBDQ is shown in Table 1, in which these symptoms were correlated with the four domains covered in the questionnaire, as well as with their total score. After multiple linear regression, comparisons were considered significant $(\mathrm{p}<0.05)$. It is worth mentioning that the correlations were negatively valued by the scores of both questionnaires (HADS and IBDO), because the higher the anxiety score, the more anxiety symptoms are observed, and the lower the IBDQ scores, the worse the quality of life. Consequently, the worse the quality of life of patients with UC, the greater the presence of anxiety symptoms.

Table 2 shows the correlation between depression symptoms and the IBDQ questionnaire. This comparison was similar to that shown in Table 1. Thus, after the multiple linear regression test, the correlations were considered significant ( $p$ $<0.05$ ) and resulted in negatively valued scores. Therefore, we found that the worse the quality of life in patients with UC, the greater the presence of symptoms of depression.

\section{Discussion}

In the present study, the population analyzed showed four times the number of women when compared to men. The same
Table 1: Comparison of anxiety symptoms versus the inflammatory bowel disease questionnaire (IBDQ) in patients with ulcerative colitis (UC)

\begin{tabular}{|c|c|c|}
\hline IBDQ & $\mathbf{R}$ & $\mathbf{P}$ \\
\hline Intestinal Symptoms & -0.380 & $<0.001$ \\
\hline Systemic Symptoms & -0.519 & $<0.001$ \\
\hline Social Aspects & -0.403 & $<0.001$ \\
\hline Emotional Aspects & -0.586 & $<0.001$ \\
\hline Total & -0.511 & $<0.001$ \\
\hline
\end{tabular}

Table 2: Comparison of depression symptoms versus the inflammatory bowel disease questionnaire (IBDQ) in patients with ulcerative colitis (UC)

\begin{tabular}{|l|l|l|}
\hline IBDQ & $\mathbf{R}$ & $\mathbf{P}$ \\
\hline Intestinal symptoms & -0.363 & $<0.001$ \\
\hline Systemic symptoms & -0.464 & $<0.001$ \\
\hline Social aspects & -0.439 & $<0.001$ \\
\hline Emotional aspects & -0.507 & $<0.001$ \\
\hline Total & -0.477 & $<0.001$ \\
\hline
\end{tabular}

peculiarity was described in the study by [11], who obtained similar results regarding the proportion of female individuals in their research, being three times higher when compared to the number of male individuals. Other studies [5,7,12-14] also reported a greater participation of women in the analysis (> $50 \%$ ). This is due to a greater concern with health and a greater endency to participate in health-related research that women mostly present [6], when carrying out a survey with 532 individuals diagnosed with $\mathrm{CU}$, reported that $74.62 \%(\mathrm{n}=397)$ declared themselves to be white, similar to the present study. Another researcher [5] also found a result in which a large part of the population declared itself white $(65.98 \%, n=65.98)$, promptly the pathology is prevalent in the white population. The mean and standard deviation of the age of the participants in the present study was $31 \pm 7.79$, similar to other findings in the literature, with mean ages of 21.2 years [6], 33 years [7] and 37.5 years [15]. Regarding marital status, the other studies $[5,13,14]$ found that married people adhered better to treatment, representing at least $66 \%$ of the population, which is close to the result obtained herein.

Moreover, the results demonstrated that there is a relationship between anxiety and depression and the symptoms of UC, influencing the quality of life of patients, corroborating other studies that evidence the presence of symptoms of anxiety and depression in individuals diagnosed with such pathology $[5,12,15]$. reported that $58 \%$ of the patients with UC exhibited symptoms of anxiety and depression, a percentage that resembles those found in the present study: $65.52 \%$ (depression) and $28.87 \%$ (anxiety). Another study, however, with patients with $\mathrm{CD}$, found that $61.7 \%(n=69)$ of the sample had symptoms of anxiety, symptoms of depression or both [7]. The mean values for anxiety and depression were $10 \pm 4.72$ and $8 \pm 4.00$, respectively, whereas, in the study by [16], the mean values were $5.26 \pm 4.47$ and $5.48 \pm 4.47$, respectively. Therefore, our results showed higher mean values for anxiety and depression when compared to the referred study [16]. 
Considering the quality of life, the parameter was lower when patients were in the period of disease activity. Tomazoni \& Benvegnú (2018) [7], also found that the period of disease activity significantly affected the quality of life of patients with IBD. It is worth mentioning that the afore mentioned study found another result similar to this, that is, 3.6\% of a sample of 110 and $7 \%$ of a sample of 97 participants, respectively, with IBD showed excellent quality of life, being the minority. It is noteworthy that the literature $[5,9,17]$ takes into account the form of presentation of symptoms, such as diarrhea, abdominal pain, bleeding of the lower digestive tract, vomiting, nausea, anorexia, and tenesmus, as factors of difficulty in adapting to the disease, which may cause symptoms of anxiety and depression in these individuals, influencing in their quality of life. Thus, it was also found in the study by Tomazoni \& Benvegnú (2018) [7] that the worse the quality of life of patients, the greater the correlation with the symptoms of anxiety and depression, significantly. During the analysis of the results in this study, it was possible to observe the relationship between nutritional status, anxiety, and depression. Lee (2017) [18] and Silva (2013) [19] reported that obese patients had symptoms of depression. In the present study, the eutrophic and overweight groups exhibited the highest values of anxiety and depression.

Finally, it is necessary to point out some of the limitations found in the present study. The fact that the survey was carried out in a virtual and impersonal manner may have influenced the interpretation and responses to the questionnaires by the participants; also, the answers depended on the truthfulness of the individuals.

\section{Conclusion}

Since UC is a chronic IBD, there is a need for its control and, consequently, the preservation of the affected individual's quality of life. In the present study, it was possible to observe the influence of the adjacent symptoms of the pathology on the patients' psychological symptoms, generation anxiety and depression as well as the impact of the stage of the disease.

\section{Acknowledgements}

We thank the members of the Human \& Animal Biosafety Research Group for their support and services during the execution of this study.

\section{References}

1. Biondo-Simões LPM, Mandelli KK, Pereira MAC, Faturi JL (2003) Opções terapêuticas para as doenças inflamatórias intestinais: revisão. Rev Bras Coloproct 23: 172-182. Link: https://bit.ly/32zXnLN

2. Roya MJB, Coutinho VF, Malagutti W, Rodrigues FSM, Ferraz RRN (2017) Comparação dos efeitos de dieta imunomoduladora com glutamina ou probióticos no tratamento da retocolite ulcerativa: síntese de evidências. Rev Saúde em Foco 9: 384-387. Link: https://bit.ly/31B7CQu

3. Meyer ALM, Teixeira MG, Kiss DR, Nahas SC, Cecconello I, et al. (2009) Quality of life in the late segment of ulcerative colitis patients submitted to restorative proctocolectomy with sphincter preservation over ten years ago. University of São Paulo. Link: https://bit.ly/3b9ycmQ

4. Molodeck NA, Soon IS, Rabi DM, Ghali WA, Ferri M, et al. (2012) Increasing incidence and prevalence of the inflammatory bowel diseases with time, based on systematic review. Gastroenterology 142: 46-54. Link: https://bit.ly/3hEoSKd

5. Costa ALS, Chaves EC (2005) Stress coping strategies and depressive symptoms among ulcerative colitis patients. Rev Esc Enferm 40: 507-514. Link: https://bit.ly/2QyEvqX

6. Mota ES (2007) Extra-intestinal manifestations in Crohn disease and ulcerative rectoclitis: prevalence and correlation with diagnosis, extension, activity, disease evolution time [dissertation]. University of São Paulo.

7. Tomazoni El, Benvegnú DM (2018) Symptoms of anxiety and depression, and quality of life of patients with Crohn's disease. Arq Gastroenterol 55: 148-153. Link: https://bit.ly/2DagJyn

8. Kurina L Goldare M, Yeates D, Gill L (2001) Depression and anxiety in people with inflammatory bowel disease. J Epidemiol Community Health 55: 716-720. Link: https://bit.ly/34HgGVV

9. Freitas TH, Andreoulakis E, Alves GS, Miranda HL, Braga LL, et al. (2015) Associations of sense of coherence with psychological distress and quality of life in inflammatory bowel disease. World J Gastroenterol 21: 6713-6727. Link: https://bit.ly/3lsaDL1

10. Marcolino JAM, Suzuki FM, Alli LAC, Gozzani JL, Mathias STLA (2007) Measurement of anxiety and depression in preoperative patients. Comparative study. Rev Bras Anestesiol 57: 157-166. Link: https://bit.ly/2EAFZ1m

11. Ficagna GB, Dalri JL, Malluta EF, Scolaro BL, Bobato ST (2020) Quality of life of patients from a multidisciplinary clinic of inflammatory bowel disease. Arq Gastroenterol 57: 8-12. Link: https://bit.ly/2QCdnqO

12. de Souza MM, Belasco AGS, de Aguilar-Nascimento JE (2008) The epidemiological profile of patients with inflammatory bowel disease in the Mato Grosso. Rev Bras Coloproct 28: 324-328. Link: https://bit.ly/2ECzPO7

13. Pontes RMA, Miszputen SJ, Ferreira-Filho OF, Miranda C, Ferraz MB (2004) Qualidade de vida em pacientes portadores de doença inflamatória intestinal: tradução para o português e validação do questionário "Inflammatory Bowel Disease Questionnaire". Arq Gastroenterol 41: 137-143. Link: https://bit.ly/3b5F4BQ

14. Soares NRM (2018) Efeito da suplementação com zinco na expressão gênica de metaloproteínas e na modulação de citocinas inflamatórias na retocolite ulcerativa [Programa de Pós-Graduação em Alimentos e Nutrição]. Universidade Federal do Piauí.

15. Byrne G, Rosenfeld G, Leung Y, Qian H, Raudzus J, et al. (2017) Prevalence of anxiety and depression in patients with inflammatory bowel disease. Canadian Journal of Gastroenterology and Hepatology. Link: https://bit.ly/2ECAglf

16. Teixeira WGJ, da Silva JH, Teixeira MG, Almeida M, Calache JE, et al. (1999) Pouchitis: extra colonic manifestation of ulcerative colitis? Rev Hosp Clín Fac Med 54: 155-158. Link: https://bit.ly/32E6j2H

17. Vivan TK, Santos BM, dos Santos CHM (2017) Quality of life of patients with inflammatory bowel disease. J Coloproctoly 37: 279-284. Link: https://bit.ly/2D9QLed

18. Lee JW (2017) Depressive symptoms and quality of life in the patients of inflammatory bowel disease. Gut Liver 11:449-450. Link: https://bit.ly/3hFuleu

19. da Silva OCAL (2013) O Perfil de Indivíduos com Doença Inflamatória Intestinal na Região o Metropolitana II do Rio de Janeiro: contribuição da enfermagem

Copyright: @ 2020 Fernandes ACS, et al. This is an open-access article distributed under the terms of the Creative Commons Attribution License, which permits unrestricted use, distribution, and $r$ eproduction in any medium, provided the original author and source are credited. 